\title{
Supplier ranking and selection in a bakery
}

\author{
Anyaeche $^{1}$, C.O. And Abegunde ${ }^{2}$, A.S. \\ ${ }^{1,2}$ Department of Industrial and Production EngineeringUniversity of Ibadan, Ibadan,Nigeria.
}

\begin{abstract}
Supplier evaluation and selection is a fundamental problem in supply chain management. Many companies may not know how to evaluate proposed suppliers to integrate the different criteria upon which they want to make their decision. A number of techniques have been employed to solve this problem but were not able tosufficiently incorporate qualitative criteria into consideration for estimation of their alternatives. A multi-criteria decision-making (MCDM) methodology, the Analytical Hierarchy Process (AHP), which takes into consideration both quantitative and qualitative criteria, was used to evaluate three suppliers of improvers (a major ingredient) for bread production in a bakery,UIB, in southwest Nigeria. This method uses a ranking scale when comparing alternatives. A consistency ratio is estimated when data have been collected to check for the consistency of judgments to ensure an accurate result is obtained with the method.

It was discovered that Supplier C adds more value to UIB because it had the highest priority weight of 0.346, although it was keenly followed by suppliers $B$ and $C$ with weights 0.336 and 0.317 respectively.

Results showed that each supplier fared well under one criteria or the other and there was a generally good performance from all suppliers.

Keywords: Analytic Hierarchy Process, Supplier Evaluation, Multi-criteria Decision Making.
\end{abstract}

\section{Introduction}

Supply Chain Management (SCM) encompasses the planning and management of all activities involved in sourcing and procurement, conversion, and all logistics management activities. Importantly, it also includes coordination and collaboration with channel partners, which can be suppliers, intermediaries, third-party service providers, and customers. In essence, SCM integrates supply and demand management within and across companies [1]. Suppliers are very important in the supply chain because their performances not only influence the benefits of the core enterprise in the Supply Chain (SC) but also determine whether a win-win situation can be achieved or not. Therefore, supplier selection is both a key problem and a tough one.

Some decision-making methods have been developed, one of which is the Analytical Hierarchy Process (AHP) technique, as useful and simple methods to deal with decision making problems.

\subsection{Problem Definition}

During the last decade, manufacturing industries have been passing through a phase of very tough competition. In this context, effective supply chain management is vital to the competitiveness of manufacturing enterprises, as it directly impacts on their ability to meet changing market demands in a timely and cost effective manner. The SC can be a network of companies which influence each other. The complexity and the large network affect one another's performance.Karthik (2006) [2] observe that the objective of the supply chain is to maximize the difference between the worth of the final product to the customer and the effort the supply chain expended in fulfilling the customer needs. This problem of balance appears not to have been fully resolved. This work is a modest attempt to contribute to the solution by focusing on the methodology for identifying the criteria for supply evaluation and the relative importance and priority. In the supply chain literature [3], the supplier selection problem is treated as an optimization problem that requires formulating a single objective function. However, not all supplier selection criteria can be quantified. The AHP makes it possible for qualitative and quantitative criteria to be considered. This is the trust of the work.

\subsection{Objectives}

The objectives of this study are as follows:

1. Identify criteria for supplier evaluation.

2. Apply the AHP to evaluate the suppliers from a selected bakery.

3. Make recommendations based on the evaluation of the suppliers.

\section{Literature Review}

The Analytic Hierarchy Process (AHP) deliveredby [4] is often referred to, eponymously, as the Saaty method. It is popular and widely used, especially in military analysis, though it is not restricted to military problems[5]. 
Many authors have studied the subject of supplier evaluation and selection. Most of these models used finalize the supplier selection decision-making process based on a set of supplier performance criteria [6]; [7]. Two of these models are summarized as follows:

\subsection{Vendor profile analysis}

Vendor profit analysis is a modified weighted point model [8]. Using Thompson's notations (see Equation (1)) the vendor profit analysis model can be expressed as follows:

$$
\mathrm{S}_{j k}=\sum_{i}^{n} w_{i} p_{i j k}
$$

Where $\mathrm{S}_{j k}$ is summated score for vendor $j$ on iteration $k$ of the simulation; $\mathrm{w}_{i}$ is importance weight attached to evaluative criteria $i ; \mathrm{p}_{i j k}$ denote the performance rating on evaluative criteria $i$ for vendor $j$ during iteration $k$ from simulation; and $n$ is the number of evaluative criteria.

The Monte Carlo simulation technique is used in this model for modelling the uncertainty associated with predicting vendor performance against the evaluative criteria instead of rating from human intuitive judgment.

\subsection{Dimensional analysis}

The evaluation process of supplier involves a series of one-on-one comparisons and can only compare two vendors each time under dimensional analysis method[9]. The Dimensional Analysis Ratio (DAR) can be obtained from Equation (2).
$\mathrm{DAR}=\prod_{i=1}^{n}\left(A_{i} / B_{i}\right)^{\mathrm{R}} i$
$i=1,2, \ldots, n^{\text {th }}$ attribute

where $\mathrm{A}_{i}$ and $\mathrm{B}_{i}$ represent $i^{\text {th }}$ attribute score of entity $\mathrm{A}$ and $\mathrm{B}$, respectively, and $\mathrm{R}_{i}$ is a relative importance assigned to attribute $i$.

\subsection{The Analytic Hierarchy Process}

\section{Methodology}

The foundation of the Analytic Hierarchy Process (AHP) is a set of axioms that carefully delimits the scope of the problem environment [4]. It is based on the well-defined mathematical structure of consistent matrices and their associated eigenvector's ability to generate true or approximate weights [4]. The AHP methodology uses a fundamental scale of absolute numbers that has been proven in practice and validated by physical and decision problem experiments. It converts individual preferences into ratio scale weights that can be combined into a linear additive weight for each alternative. The comparison scale is summarised in table 1.

Table 1: AHP fundamental comparison scale

Source: [10]

\begin{tabular}{|c|c|}
\hline \multicolumn{2}{|c|}{ For any pair objectives $i, j$} \\
\hline Score & Relative Importance \\
\hline 1 & Objective $i$ and $j$ are of equal importance \\
\hline 3 & Objective $i$ is weakly more important than $j$ \\
\hline 5 & Objective $i$ is strongly more important than $j$ \\
\hline 7 & Objective $i$ is very strongly important than $j$ \\
\hline 9 & Objective $i$ is absolutely more important than $j$ \\
\hline \multicolumn{2}{|c|}{ Note: $2,4,6,8$ are the intermediate values } \\
\hline
\end{tabular}

\subsection{Model development}

The following steps associated with the AHP method for decision making are used:

1. Clearly define the decision problem and determine its goal.

2. Structure the hierarchy from top through the intermediate levels to the lowest level

3. Compose a pair-wise comparison decision matrix.

Let 'A' represent an $a^{n \times n}$ pair-wise comparison matrix and can be expressed as

$$
\mathrm{A}=\left[a_{i j}\right]=\left[\begin{array}{ccc}
1 & \cdots & a_{1 n} \\
\vdots & \ddots & \vdots \\
\frac{1}{a_{1 n}} & \cdots & 1
\end{array}\right]
$$

where $\mathrm{a}_{i j}=1$ and $\mathrm{i}, \mathrm{j}=1,2, \ldots, \mathrm{n}$. $\mathrm{L}$ et $\mathrm{C}_{1}, \mathrm{C}_{2}, \ldots, \mathrm{C}_{n}$ denote the set of criteria, while $\mathrm{a}_{\mathrm{ij}}$ represents a quantified judgment on a pair of criteria $\mathrm{C}_{i}$ and $\mathrm{C}_{j}$.

4. Calculate the Eigenvalue and Eigenvector

The normalization of the geometric mean (NGM) method is used to determine the importance degrees of DMs requirements. Let $\mathrm{W}_{i}$ denoted the importance degree (weight) for the ith criteria, then 


$$
w_{i}=\frac{\sqrt[n]{\prod_{j=1}^{n} a_{i j}}}{\sum_{i=1}^{n} \sqrt[n]{\prod_{j=1}^{n} a_{i j}}}, \quad i, j=1,2, \ldots, n .
$$

wheren is the number of criteria.

In addition, the Maximum Eigenvalue, $\lambda_{\max }$, also known as Principal Eigenvalue, can be calculated by equation (5) and (6)

$$
\mathrm{A}=\left[\begin{array}{ccc}
1 & \cdots & a_{1 n} \\
\vdots & \ddots & \vdots \\
1 & \cdots & 1
\end{array}\right] *\left[\begin{array}{c}
w_{i} \\
\vdots \\
a_{1 n}
\end{array}\right.
$$

$\lambda_{\max }=(1 / n) *\left(W^{\prime}{ }_{1} / W_{1}+W_{2}^{\prime} / W_{2}^{\prime}+\ldots+W_{n}^{\prime} / W_{n}\right)$

5. Estimate the Consistency Analysis (Consistency Index and Consistency Ratio)

Saaty[4] explained that with the maximum eigenvalue, $\lambda_{\max }$, a Consistency Index (CI) can be calculated by

$$
\mathrm{CI}=\frac{\lambda_{\max }-n}{n-1}
$$

In equation (7), if $\mathrm{CI}=0$, the evaluation for the pair-wise comparison matrix is implied to be completely consistent. Particularly, the closer the maximal eigenvalue is to $n$ the more consistent the evaluation is. Generally, a consistency ratio (CR) can be used as a guidance to check for consistency.

The formulation of CR is [4]:

$$
\mathrm{CR}=\frac{\mathrm{CI}}{\mathrm{RI}}
$$

where RI is the average index with the value obtained by different orders of the pair-wise comparison matrices. If $\mathrm{CR}$ is less than 0.1 , the judgements are consistent, so the derived weights can be used.

Table 2: Random Index (RI) for the factors used in the decision making process

\begin{tabular}{|c|c|c|c|c|c|c|c|c|c|c|c|c|}
\hline$N$ & 1 & 2 & 3 & 4 & 5 & 6 & 7 & 8 & 9 & 10 & 11 & 12 \\
\hline$R I$ & 0 & 0 & 0.58 & 0.9 & 1.12 & 1.24 & 1.32 & 1.41 & 1.45 & 1.49 & 1.51 & 1.58 \\
\hline
\end{tabular}

Source: [11]

\subsection{The Criteria}

For an efficient examination of the suppliers by AHP process, three suppliers are evaluated with five main criteria which are Quality, Performance, Service, Cost, and Supplier Profile[12]. The sub-criteria (attributes) for each criterion are given below:

1. Quality (QLTY)
i. $\quad$ Audit Result (AR)
ii. Quality defects (QD)
iii. Defects analysis (DA)
iv. Documentation (DOC)

2. Performance (PERF)
i. Customer Request Date (CRD)
ii. Original Promised Date (OPD)
iii. Average Late Days (ALD)
iv. Turn Around Time (TAT)
v. $\quad$ Lead Time (LT)

3. Service (SERV)

i. Ease of Communication (EOC)

ii. Process Flexibility (PF)

iii. Response to Changes (RC)

iv. Information Sharing (IS)

v. Customer Service (CS)

4. Cost (COST)

i. Price competitiveness (PCP)

ii. Product Cost (PC)

5. Supplier Profile (SP)
i. Location (LOC)
ii. Financial States (FS)
iii. Facility (FAC)
iv. Capacity (CAP) 


\section{v. Supplier Cooperation (SC)}

\subsection{The company}

\section{Application}

The company used as a case study is a bakery, UIB, in southwest Nigeria. The major ingredients used at the bakery are flour, yeast, water, sugar, butter, salt and improvers. UIB has three major suppliers for the improvers, referred to as Supplier A, Supplier B, and Supplier C. The manager wishes to evaluate these suppliers based on the various criteria decided by the company. A structured questionnaire was developed and all the criteria we re rated based on the experience of the decision-maker and other key operators.

\subsection{Calculations}

This sectionshows the calculations made using the Analytical Hierarchy Process. Table 3 below shows how the matrix developed for all the main criteria. In deciding the relations between the criteria, the fundamental scale was used.

Table 3: Criteria Pair-wise comparison matrix

\begin{tabular}{|c|c|c|c|c|c|}
\multicolumn{1}{c|}{} & QLTY & PERF & SERV & COST & SP \\
\hline QLTY & 1 & 3 & 3 & 3 & 5 \\
\hline PERF & $1 / 3$ & 1 & 3 & $1 / 3$ & 5 \\
\hline SERV & $1 / 3$ & $1 / 3$ & 1 & $1 / 3$ & 3 \\
\hline COST & $1 / 3$ & 3 & 3 & 1 & 5 \\
\hline SP & $1 / 5$ & $1 / 5$ & $1 / 3$ & $1 / 5$ & 1 \\
\hline
\end{tabular}

After the matrix of the main criteria was conducted, the next step was the normalization value which were used as weight of each criterion in the analytical hierarchy process. In Table 4 below, the normalized value and the eigenvector for the main criteria are as shown:

Table 4: Criteria Pair-wise comparison matrix showing eigenvalue and normalized value

\begin{tabular}{|c|c|c|c|c|c|c|c|}
\cline { 2 - 8 } \multicolumn{1}{c|}{} & QLTY & PERF & SERV & COST & SP & G.M & $W$ \\
\hline QLTY & 1 & 3 & 3 & 3 & 5 & 2.667 & 0.414 \\
\hline PERF & $1 / 3$ & 1 & 3 & $1 / 3$ & 5 & 1.107 & 0.172 \\
\hline SERV & $1 / 3$ & $1 / 3$ & 1 & $1 / 3$ & 3 & 0.644 & 0.100 \\
\hline COST & $1 / 3$ & 3 & 3 & 1 & 5 & 1.719 & 0.267 \\
\hline SP & $1 / 5$ & $1 / 5$ & $1 / 3$ & $1 / 5$ & 1 & 0.305 & 0.047 \\
\hline
\end{tabular}

\subsection{The Consistency Ratio (CR)}

The consistency ratio is presented in table 5 below:

Table 5: Calculation of the eigenvalue and consistency ratio

\begin{tabular}{|c|c|c|c|c|c|c|c|c|c|}
\hline & QLTY & PERF & SERV & COST & SP & G.M & $W$ & $W^{\prime}$ & $W^{\prime} / W$ \\
\hline QLTY & 1 & 3 & 3 & 3 & 5 & 2.667 & 0.414 & 2.266 & 5.47 \\
\hline PERF & $1 / 3$ & 1 & 3 & $1 / 3$ & 5 & 1.107 & 0.172 & 0.934 & 5.43 \\
\hline SERV & $1 / 3$ & $1 / 3$ & 1 & $1 / 3$ & 3 & 0.644 & 0.100 & 0.525 & 5.25 \\
\hline COST & $1 / 3$ & 3 & 3 & 1 & 5 & 1.719 & 0.267 & 1.465 & 5.45 \\
\hline SP & $1 / 5$ & $1 / 5$ & $1 / 3$ & $1 / 5$ & 1 & 0.305 & 0.047 & 0.251 & 5.34 \\
\hline
\end{tabular}

This value of CR was found to be 0.09 which implies that judgements are consistent because it is less than 0.1 . A summary of the evaluations is presented in tale 6 below:

Table 6: Main and Sub-criteria weights

\begin{tabular}{|l|c|c|c|c|c|}
\hline $\begin{array}{l}\text { Main criteria } \\
\text { Criteria weight }\end{array}$ & $\begin{array}{c}\text { Quality } \\
0.414\end{array}$ & $\begin{array}{c}\text { Performance } \\
0.172\end{array}$ & $\begin{array}{c}\text { Service } \\
0.100\end{array}$ & $\begin{array}{c}\text { Cost } \\
0.267\end{array}$ & $\begin{array}{c}\text { Supplier Profile } \\
0.047\end{array}$ \\
\hline \multirow{2}{*}{$\begin{array}{l}\text { Sub-criteria } \\
\text { Criteria weight }\end{array}$} & AA & CRD & EOC & PCP & LOC \\
\cline { 2 - 6 } & 0.045 & 0.356 & 0.180 & 0.500 & 0.087 \\
\cline { 2 - 6 } & QD & OPD & PF & PC & FS \\
\cline { 2 - 6 } & 0.644 & 0.148 & 0.279 & 0.500 & 0.087 \\
\cline { 2 - 6 } & DA & ALD & RC & & FAC \\
\cline { 2 - 6 } & 0.229 & 0.229 & 0.067 & & 0.210 \\
\hline
\end{tabular}




\begin{tabular}{|c|c|c|c|c|c|}
\multirow{4}{*}{ DOC } & \multicolumn{2}{|c|}{ TAT } & IS & \multicolumn{2}{|c|}{ CAP } \\
\cline { 2 - 6 } & 0.083 & 0.148 & 0.224 & \multicolumn{2}{|c|}{ SC } \\
\cline { 2 - 6 } & & LT & CS & \multicolumn{2}{|c|}{0.406} \\
\hline
\end{tabular}

Givenbelow are the results from AHP of the suppliers based on each criterion.

\subsection{Best supplier in Quality criterion}

Table 7: Final weighted result for each supplier in quality criterion

\begin{tabular}{|c|c|c|}
\hline SUPPLIER & Weight & Rank \\
\hline A & 0.254 & 3 \\
\hline B & 0.391 & 1 \\
\hline C & 0.355 & 2 \\
\hline
\end{tabular}

Best supplier in Performance criterion

Table 8: Final weighted result for each supplier in performance criterion

\begin{tabular}{|c|c|c|}
\hline SUPPLIER & Weight & Rank \\
\hline A & 0.251 & 3 \\
\hline B & 0.463 & 1 \\
\hline C & 0.286 & 2 \\
\hline
\end{tabular}

Best Supplier by Service Criterion

Table 9: Final weighted result for each supplier in Service criterion

\begin{tabular}{|c|c|c|}
\hline SUPPLIER & Weight & Rank \\
\hline A & 0.579 & 1 \\
\hline B & 0.322 & 2 \\
\hline C & 0.096 & 3 \\
\hline
\end{tabular}

\section{Best Supplier by Cost Criterion}

Table 10: Final weighted result for each supplier in cost criteria

\begin{tabular}{|c|c|c|}
\hline SUPPLIER & Weight & Rank \\
\hline A & 0.349 & 2 \\
\hline B & 0.181 & 3 \\
\hline C & 0.469 & 1 \\
\hline
\end{tabular}

\section{Best Supplier by Supplier Profile Criterion}

Table 11: Final weighted result for each supplier in supplier profile section

\begin{tabular}{|c|c|c|}
\hline SUPPLIER & Weight & Rank \\
\hline A & 0.379 & 1 \\
\hline B & 0.292 & 3 \\
\hline C & 0.328 & 2 \\
\hline
\end{tabular}

Best supplier according to AHP

From table 12, it can be seen that from all the matrices used in the calculation, the ranking of the suppliers is a very close run. This kind of close competition was really not so obvious at the beginning of AHP valuation. However when examining the bigger picture, all of the suppliers performed very well and while the difference between the best and the last supplier was only 0.029 which is little over $8 \%$ of difference.

Table 12: Final weights and ranking for all of the suppliers according to AHP

\begin{tabular}{|l|l|l|}
\hline SUPPLIER & Weight & Rank \\
\hline C & 0.346 & 1 \\
\hline B & 0.336 & 2 \\
\hline A & 0.317 & 3 \\
\hline
\end{tabular}

\section{Conclusions}

From the analysis done in the section, the following conclusions can be made:

1. The criteria for supplier evaluation were identified. 
2. AHP was used to evaluate supplier and results show that supplier B ranks best in terms of the quality criteria, closely followed by supplier $\mathrm{C}$ but supplier A gives the least quality.

3. The overall AHP ranking showed that all suppliers are close but supplier $\mathrm{C}$ seems to have a slight edge over others.

\section{References}

[1] Mamun, H, n.d., Supply Chain Management (SCM): Theory and Evolution, American International University, Bangladesh, viewed 10 October $2012,<$ http://>

[2] Karthik, V, (2006), 'An integrated supplier selection methodology for designing robust supply chains', IEEE International Conference on Management of Innovation and Technology, pp. 906-910.

[3] Kuwait Chapter of Arabian Journal of Business and Management Review (2012), Application of Analytical Hierarchy Process (AHP) Technique to evaluate and select Suppliers in an Effective Supply Chain, Vol. 1, No. 8.

[4] Saaty TL, (1980), Analytic Hierarchy Process, McGraw-Hill International, New York.

[5] Coyle R G (1989), Defence Planning, Vol. 5, No. 4, pp. 353-367

[6] Youssef, MA, Zairi, M and Mohanty, B (1996), 'Supplier selection in an advanced manufacturing technology environment: An optimization model', Benchmark Quality Management Technology, Vol. 3, No. 4, pp. 60-72.

[7] i WN, Low C, (2005), 'Supplier evaluation and selection using Taguchi loss functions', International Journal of Advanced Manufacturing Technology No. 26, pp. 55-160.

[8] Thompson, KN, (1990), Vendor profile analysis, Journal for Purchasing Material. Management, Vol.26, No. 4, pp. 11-18.

[9] Probability and Statistic Forum (2010), Supplier selection project using an integratedDelphi, AHP and Taguchi loss function, Vol. 3, pp. 118-134.

[10] Saaty TL (2008), 'The Analytic Hierarchy Process', International Journal of Services Science, Vol. 1, No. 1, pp. 83-98.

[11] Coyle R G (2004), AHP Technique, Practical Strategy, , Pearson educational Limited, Open Access Material, Accessed June, 2013.

[12] Mikael, JB, (2009), 'Supplier Evaluation using Analytic Hierarchy Process', Master's thesis, Lappeenranta University of Technology, Helsinki. 